\title{
Safety Culture - The Hard Rock that Turns Back Our Spade?
}

\author{
Ulrike Bollmann \\ Institute for Work and Health of the DGUV Koenigsbruecker Landstr. 2, 01109 Dresden, Germany
}

Copyright $(2016$ by authors, all rights reserved. Authors agree that this article remains permanently open access under the terms of the Creative Commons Attribution License 4.0 International License

\begin{abstract}
Safety culture is the springboard for developing a culture of prevention. Without safety (Vision Zero) there can be no culture of prevention. However, the dominant functionalist approaches to safety culture fall short. Human action cannot be understood exclusively rationally or by being reduced to behaviour. A culture of prevention exists nowhere else but in human actions, in this "between" that exists between humans and that humans create as a common sphere of action. Further development of a culture of prevention through the concept of safety culture requires qualitative field research.
\end{abstract}

Keywords Safety Culture, Culture of Prevention, Action, Behaviour, Qualitative Research

\section{Introduction}

In terms of the concept of culture, occupational safety and health leaves its traditional comfort zone of being justified through traditional engineering and economic sciences.

The use of terms such as safety culture or culture of prevention provokes us into dealing with something that cannot be put into rules without becoming meaningless or trivial at the same time.

What does it mean to follow a rule? The modern English word rule comes from Old French riule and originally from Latin regula. Its earliest sense was to describe the guidelines and charter used by Benedictine monks who had taken the word from the Apostle Paul in 2 Corinthians 10. Only later was the word used in a broader sense to describe a guideline for behaviour or actions (Winsbeke, 1220). A rule provides guidance in one's doings (Christian Wolff, 1720) or a rule is the notion of a general condition according to which a certain manifold can be set (Immanuel Kant). Since the Age of Enlightenment, a rule is considered to be set by man himself and the word rule is associated with rational thinking and reasoning (Lyotard 1987, 164). With the "Foundational Crisis" in the natural sciences at the end of the $19^{\text {th }}$ century and beginning of the $20^{\text {th }}$ century, the idea of a completely rational foundation for rules was challenged. Gödel's incompleteness theorem states that rules within an arithmetic system can be accepted but outside of this system they cannot be scientifically validated through their own consistency (Kurt Gödel, 1931; cf. Bollmann 2001, 209 and 195).

'How am I able to obey a rule?' If this is not a question about causes, then it is about the justification for my following the rule in the way I do. If I have exhausted the justifications, I have reached bedrock and my spade is turned. Then I am inclined to say: "This is simply what I do." (Wittgenstein 1977, 133: PI \#217).

In the following, the development of the concept of safety culture and culture of prevention will be explained in broad strokes and the difference between the two concepts will be described. This is based on the assumption that distinguishing between action and production or action and behaviour is a prerequisite for the development of a sustainable culture of prevention. This will be followed by proposals for further elaboration of the concept of a culture of prevention.

\section{The Humus of Prevention}

\subsection{The Current State of the Discussion on Safety Culture}

Safety culture is the springboard for developing a culture of prevention. Without safety (Vision Zero) there can be no culture of prevention. Similar to the foundational crisis of the natural sciences, questioning their completely rational foundation (see above), it was the event at Chernobyl, that challenged the traditional paradigm of safety science based on the principles of causality and control. On 26 April 1986, the Chernobyl disaster occurred in Ukraine. Since then, there has been systematic debate and empirical research on the topic of safety culture. It is critical to realise that previous concepts of safety were no longer sufficient to explain in rational terms the complexity of the events at Chernobyl (and 
other catastrophes now and in the past). Thus, the concept of safety culture was agreed upon in order to describe the wide scope of technical, human and organisational factors that contributed to the disaster (International Nuclear Safety Advisory Group, INSAG 1988; see Fahlbruch/Schöbel 2009, 48). In order to describe the move from technical safety to the concept of safety culture, Andrew Hale distinguishes between three ages of safety: the first is the age of technology, the second is the age of human factors and the third is the age of safety management which involves integrated safety, health and environmental management systems (Hale, 1998). Babette Fahlbruch and Markus Schöbel designate the third age as a "socio-technical" phase: based on the approach of socio-technical systems, the interaction between technical, human and organisational factors throughout the entire organisation are now the focal point. In addition to this socio-technical phase, there is an additional fourth inter-organisational phase which partly overlaps the socio-technical phase: the focus for Fahlbruch and Schöbel is now the interaction between different people and organisations (Fahlbruch/Schöbel 2009, 49).

There followed years of intensive empirical research on the topic of safety culture. In 2010, Frank Guldenmund called for a theoretical foundation of safety culture as a concept (Guldenmund 2010, 4) and Dov Zohar has criticized the ambiguity of existing concepts (Zohar 2010, 1521). Zohar is specifically referring to the interchangeability of the terms safety culture and safety climate (see Health \& Safety Laboratory 2013, 4). After more than 25 years of empirical research on the topic of safety culture it would appear that the topic of safety culture has come to an end. In his current study on organisational culture, David Borys farewells the concept of safety culture. The concept is confusing and ambiguous, the evidence of its importance in practice is inadequate: " $(\mathrm{T})$ here is little evidence of a direct relationship between it and safety performance" (Borys 2014, 17; 30). He suggests abandoning the search for a definition of safety culture and recommends returning to the organisational and managements practices that have an immediate and direct influence on workplace safety. The concept of organisational culture could certainly remain as a metaphor; the main point is that the naturalistic fallacy of trying to study safety culture as a material object would be avoided or as Stian Antonsen so succinctly put it: There is "no such 'thing' as a safety culture" (Antonsen, 2009, 24).

Frank Guldenmund once recommended Edger H. Schein's Model of Organisational Culture as a theoretical reference model (Schein 2004, $1^{\text {st }}$ Edition 1985). This represented huge progress given an "a-theoretical" approach to research which focuses on a simple plan-do-check-act model. At the same time, however, the use of Schein's model raises issues: when analysing an organisation's culture it is no longer enough to explore the world of representational artefacts, it is also important to take into consideration the shared values in the organization and the implicit fundamental beliefs of the employees. The focus of interest is no longer on behaviour and attitudes but rather the individual notions of health and safety which can vary depending on region, social background, gender and age. In fact, ethnologists and anthropologists would ideally be involved in safety research. However, apart from a few exceptions this is not the case (for exceptions see Dekker, 2015; Haukelid 2008). Research on safety culture has mainly followed a functionalist approach and not an interpretative one (cf. Borys 2014, 20 following Dekker 2014).

\subsection{The Current State of the Discussion on a Culture of Prevention}

Whereas the catalyst for addressing the topic of safety culture was a technical disaster, the "birth" of the concept of a culture of prevention goes back to a political decision. On 29 June 2008 at the XVIII World Congress on Safety and Health at Work, the Seoul Declaration was adopted. With this declaration, the International Labour Organization (ILO), the International Social Security Association (ISSA) and the Korea Occupational Safety and Health Agency (KOSHA) expressed their joint desire to build a global culture of safety and health at work "by ensuring that priority is given to occupational safety and health in national agendas and by building and maintaining a national preventative safety and health culture". Consequently, at the 2011 XIX World Congress in Istanbul, the ISSA International Section for a Culture of Prevention was established. The term culture of prevention was selected on purpose in order to avoid the naturalistic fallacy from the very outset. At the $3^{\text {rd }}$ International Strategy Conference on Health and Safety at Work in Dresden in 2013, an action plan for analysing and implementing the concept of a culture of prevention was agreed upon. In the same year, scientists from around the world met in Helsinki at the International Symposium to disuss a culture of prevention. At the XX World Congress on Safety and Health at Work in Frankfurt in 2014, the topic of a culture of prevention was one of three main themes. The congress in Frankfurt also allowed organisers and visitors to fulfil the dream of experiencing live a culture of prevention.

The German Social Accident Insurance is currently preparing a national campaign on the topic of a culture of prevention which will commence in 2017. Similar to the discussion on safety culture, there will be protests raised that a definition of culture of prevention is lacking and questions will be asked about its practical relevance and whether it can be empirically verified. The ISSA International Section for a Culture of Prevention has commissioned the development of indicators for measuring a culture of prevention. Initial results are already available (White 2015).

But what legitimises a culture of prevention concept that goes beyond the current concepts of safety culture (and health culture)?

\section{The Bedrock of Practice}

The established way of determining an organisation's 
culture is: That's how we do it here (see Borys 2014, 8 with reference to Bower 1966 and Deal/Kennedy 1982). Practice is that which we have in common and which cannot be turned back. However, the debate on safety culture and culture of prevention is based on what understanding of practice?

In everyday language, practice and theory are at odds with one another. This compares to Aristotle's distinction between practice in its narrow and broad senses.

Aristotle sees practice in its narrow sense as making and producing in the sense of an activity that is directed to an end beyond itself such as building, learning or walking. As such, practice is contrary to theory as an activity whose goal is knowledge of the truth in general. Practice in its broad sense refers to an activity whose end is in itself, such as the human pursuit of life, of being happy, seeing, pondering, thinking activities which include both the theory and the practice in its narrow sense (Wildfeuer 2011, 1777).

\subsection{The Distinction between Action and Production}

In examining the question "What are we actually doing, when we act?", Hanna Arendt refers back to this distinction and the difference between action and production.

Production, as the prime example of an activity directed to an external purpose (Aristotle also speaks here of poiesis) has the following characteristics:

(1) The production process takes place under the direction of a model.

(2) Deviations in the product from the model are seen as errors. Disruptions are to be eliminated.

(3) Production processes require stability that is independent of the situation and whose complexity is minimised. They are "anonymous and impersonal" (Wildfeuer 2011, 1787). The human being can also be a disrupting factor here. Where technically feasible, the human being is replaced with a machine.

(4) The production process is "an identical process ... repeatable at any time" (Wildfeuer 2011, 1788). In the production process it is all about reproducibility.

(5) Production is always associated with a particular purpose. This purpose, however, is never the product itself. The product itself fulfils a purpose that goes beyond itself. The product is the means to an end. Thus, producing something only has an instrumental value. This can also include the production of life-serving products which serve the safety and health of human beings (Wildfeuer 2011, 1788).

Whereas the production process is characterised by anonymity and impersonality, actions are always associated with a person (see Wildfeuer 2011, 1791; cf. Arendt 1981, 175 and 187).

(1) Humans differentiate themselves from one another in their actions (and their speech). In our actions we cannot be replaced by another. Then the actions would become something different. Our actions, therefore, make us unique.

(2) To act means starting something new, from our own initiative and our own freedom (Arendt 1981, 166).

(3) To every new start belongs the "unpredictability of the outcome" (Arendt 1981, 166). Thus, human action eludes predictability. Hannah Arendt speaks of human beings simply having a "talent for the absolutely unpredictable" (Arendt 1981, 167). Human action is subject to the principle condition of uncertainty (Wildfeuer 2011, 1789).

(4) We cannot possess human actions and words like we can things, even if two people are speaking about something very specific. Our actions and speech relate to the "space" that exists between people and which people create as a common sphere of action. Hannah Arendt referred to this reality as "the fabric of human relationships and affairs, whereby the metaphor of fabric attempts to do justice to the physical intangibility of the phenomenon" (Arendt, 1981, 173).

(5) However, "the fabric of human relationships and affairs precedes all individual action and speech" (Arendt 1981, 174). The actor is, thus, neither sovereign nor constructor; they merely add their own thread to "an already woven pattern" (Arendt loc. cit.). What remains at the end are stories and histories which, strictly speaking, can only be the "object" of an analysis when the person is no longer alive (Arendt 1981, 175). In terms of organisational culture and safety culture, the concept of the "pattern" is encountered in Schein, Zohar and Guldenmund.

(6) Because we always act among others we are both offender and victim at the same time. Every action "not only triggers a 're-action' but also elicits distinct action that in turn affects another actor" (Arendt 1981, 182). The number of people that are affected by our actions and our suffering is, in principle, boundless because the consequences of our actions are unforeseeable (Wildfeuer 2011, 1792).

Distinguishing between action and production results in two things: Firstly, the process of acting cannot be reduced to the process of producing (Wildfeuer 2011, 1794). Actions are fundamentally complicated and are limited in their ability to be rationally planned due to the "entanglement of human relationships and affairs". "Practice is, therefore, always highly situational, structurally complex and is always subject to risk and uncertainty" (Wildfeuer 2011, 1792). Secondly, "dealing with other people cannot follow the activity of producing". This "contradicts the dignity of human beings, who, according to Immanuel Kant, must be treated as an end and never simply as a means" (Wildfeuer 2011, 1794).

\subsection{The Distinction between Actions and Behaviour}

In order to compensate for damages caused by humans through the unpredictability of the consequences of their 
actions, Burrhus Frederic Skinner developed his technology of behaviour. At the centre of this is the method of operant conditioning: only observable behaviour is real, the behaviour that is controlled by environmental stimuli that is either punitive or rewarding. According to Skinner, everything else is mere illusion. The telling title of one of his works is: Beyond Freedom and Dignity. In the technology of behaviour and the positive improvement in socially accepted behaviour, he saw the opportunity to achieve a peaceful and conflict-free society. The key prerequisite for this is to rule out ideas, feelings, character traits and human will everything that makes up the contradictory nature of human actions and which has advanced humans so little in the last two and a half thousand years (Skinner 1973).

The concept of Behavioural Based Safety (BBS) also works on the basic principle of operative conditioning. However, the concept has now been criticised because of the following reasons:

(1) The measures put in place do not result in a lasting effect. From a certain level (BBS plateau), improvements are hardly detectable. People become accustomed to environmental stimuli such as warning signs and safety rules.

(2) The consequences of behaviour are only mediated through external mechanisms such as intervention on the part of a supervisor, colleagues or a safety officer.

(3) BBS is focused more on employee behaviour and less on that of supervisors and managers.

(4) Effective implementation of BBS requires a particular sequence of regular interventions whose theoretical rationale is not always clear to a practitioner.

(Gutierrez 2012, 1f.)

The cognitive revolution in the 1960s, involving Skinner himself, was supposed to redress this (Skinner 1957; cf. Chomsky 1967/1959). Cognitive psychologists assume that behaviour is not caused by environmental stimuli but rather that human experiences and behaviour are a result of cognitive processes. The "black box" of behaviourism is opened in an attempt to factor cognitive processes (particularly learning, thinking, perceiving and speaking) into explaining human behaviour and actions. However, the difference between cognition and behaviour is not clearly defined, which can be attributed to the functionalist slant of cognitive psychology for information processing and problem solving (Koch 2015, 12).

More recently, an attempt has been made to link the BBS approach with the safety culture approach. In 2004, David M. DeJoy put out a paper in which he analysed how BBS and safety culture can complement one other in their strengths and weaknesses. His paper was immediately awarded a prize. A strength of the BBS approach, for example, is that BBS reinforces desired safety behaviour. Thus, from a positive perspective, BBS is different from many other traditional safety programmes which are based on the enforcement of safety rules and the punishment of safety violations.
Nevertheless, BBS can also be criticised for its individualistic approach, insufficient consideration of environmental factors and for focusing too much on direct causes and ignoring the chain of effect. However, the weaknesses of the behavioural approach are actually the strengths of the cultural approach. For example, the cultural approaches have a better overview of changes at the organisational level and are, generally speaking, more comprehensive. Nonetheless, assessments of organisational culture are often subjective and are difficult to reproduce or even verify. This contrasts with the BBS approach which is largely objective and empirical. DeJoy's statements culminate in an impressive multilevel problem-solving process within an organisation. He called this multilevel approach the "operational engine" in order to generate all factors that make up the "this-is-how-we-do-it-here" in an organisation (DeJoy 2005, 118f). Thus, the BBS approach is the perfect social technology. Cultural change, which, according to DeJoy, only manifests itself in behaviour (DeJoy 2005, 121) is merely the means to an end in a better functioning organisation.

\subsection{Against the Dominance of the Functional Paradigm}

It is thanks to Lee G. Bolman and Terrence E. Deal that attention has been drawn to the differences between various theoretical categories or traditions. They call these "frames" and they are derived from existing theories of organisation. At the core of their work are the topics of leadership and management (Bolman \& Deal (1984) 1989; 1992). Bolman and Deal have identified four frames. The structural frame, the human resource frame, the political frame and the symbolic frame.

"The structural frame emphasizes rationality, efficiency, structure, and policies. Structural leaders value analysis and data, keep their eye on the bottom line, set clear directions, hold people accountable for results, and try to solve organizational problems with new policies and rules - or through restructuring. The human resource frame focuses on the interaction between individual and organizational needs. Human resource leaders value relationships and feelings and seek to lead through facilitation and empowerment. The political frame emphasizes conflict among different groups and interests for scarce resources. Political leaders are advocates and negotiators who spend much of their time networking, creating coalitions, building a power base, and negotiating compromises. The symbolic frame sees a chaotic world in which meaning and predictability are socially constructed and facts are interpretative rather than objective. Symbolic leaders pay diligent attention to myth, ritual, ceremony, stories, and other symbolic forms." (Bolman \& Deal 1992, 314f.)

In a study on leadership and management in educational 
institutions in the USA and Singapore, Bolman \& Deal came up with the following propositions:

(1) In a world of increasing ambiguity and complexity, both managers and supervisors need to be able to use more than just one of these theoretical frames. The ability to have multiple perspectives improves their ability to make judgements and increases the effectiveness of their actions.

(2) Leadership is contextual. Different situations require different ways and patterns of thinking.

Andrew Hale used Bolman \& Deal's four frames as the basis of his 1998 meta-analysis of studies on the organisational aspects of safety, health and the environment. Not surprisingly, he identified the dominance of the structural frame in the studies he analysed and he drew from this two conclusions. Firstly, he attributes the dominance of the structural frame to the idea that OSH management systems have to be governed and dominated by rules (Hale 1998. 153, 156). Secondly, he stated that “... this limited structural approach misses three-quarters of the factors that have proven links to performance" (Hale 1998, 156).

\section{Results and Discussion}

Quo vadis culture of prevention?

Where to now with the culture of prevention? (see Gospel according to John 13, 36)

(1) Safety first: the results of the theoretical and scientific examination of safety culture form the basis for the further development of the concept of a culture of prevention.

(2) It is necessary to have a clear distinction between the various theoretical approaches, that is, between the structural frame and the symbolic frame, between a functionalist approach (operational engine) and an interpretive approach. A change of perspective may be appropriate here but only when no single perspective is dominant.

(3) In the context of a culture of prevention, it cannot be assumed that safety and health are objective entities. Rather an analysis must be done of what the interactive patterns look like in which safety and health are said to be significant. Dov Zohar has the edge here with his concept of safety climate. Zohar states that "safety climate perceptions should be viewed from the perspective of 'procedures-as-pattern' rather than to individual safety practices or procedures viewed in isolation (Zohar 2010, 1518). According to Zohar, these patterns can be identified in an organisation from: a) how OSH is prioritised compared with other priorities, b) the gap between espoused and enacted priorities, and c) the level of consistency between policies, procedures and practices (Eichendorf/Bollmann 2014, 41).
(4) It is also imperative to do qualitative research. However, not in the sense of reconstructing subjective perspectives of health and safety but rather in the sense of visualising the (social) phenomena that underlie these perspectives. For example, a theoretical foundation for the concept of a culture of prevention could follow the grounded theory - a qualitative research approach from the social sciences in which data collection, analysis and theory formation are in a reciprocal relationship (Strübing 2004; Strauss 1996). Similarly, anthropological approaches and their ethnographic methods could also prove valuable (Haukelid 2008; Wulf 2015).

The spade of the rational-functionalist paradigm is turned back by the fundamental complexity and unpredictability of human action. A culture of prevention exists nowhere else but in human actions, in this "between" that exists between humans and that humans create as a common sphere of action.

Normative assumptions about safety and health cannot be made because they are continually made up of human actions. Safe and healthy actions are inevitably a result of choices based on our presumptions (conscious and preconscious) with regard to each problem and context. The constitution process is "far ahead of any cognitive representation" and is "already embedded into our everyday routines and habits" (Strübing 2007, 130).

A culture of prevention is always context-bound. Research on culture of prevention is, in the best case scenario, field research - the analysis of specific situations is at the fore. This type of analysis is preferably done where crises cause daily routines to falter. Some specific examples of this are:

- a near-miss accident not being reported because of a power struggle in an institution;

- labour inspectors having to personally identify with their new task of assessing psychological health risks;

- a safety expert in a care facility is too late in recognising a colleague's suicide risk;

- drug abuse (alcohol, psychotropic drugs) is part of a company's daily life;

- a school principal is torn between the concept of a health-promoting school and the bureaucratic and economic conditions in the school;

- a colleague returns to work after a year's absence as part of a reintegration programme.

According to grounded theory, cases are not selected based on how representative they are but rather whether they can provide new insights, for example, until theoretical sampling for a concept of culture of prevention is achieved (Grounded Theory 2015). The key categories of a culture of prevention could be determined by permanently comparing differences, commonalties and action patterns. In addition, a new, reflective understanding of many everyday functional 
correlations would be achieved (see Wulf 2012).

Due to the fundamental unpredictability of human action, it could turn out that the concept of a culture of prevention has less of a systematic character and more of a heuristic character. This, however, is not necessarily disadvantageous but rather makes it possible to specify and modify according to the context (Wulf 2012).

Quo vadis? There's a lot to do. Let's get to it.

\section{REFERENCES}

[1] Antonsen, Stian (2009). Safety Culture: Theory, method and improvement

[2] Arendt, Hannah (1998). Vita Activa oder Vom tätigen Leben, 1981, 2nd edition 1998; Original: The Human Condition, 1958

[3] Bollmann, Ulrike (2001). Wandlungen neuzeitlichen Wissens. Historisch-systematische Analysen aus pädagogischer Sicht

[4] Bolman, Lee G.; Deal, Terrence E. (1992). Leading and Managing: Effects of Context, Culture, and Gender

[5] Bolman, Lee G.; Deal, Terrence E. (1989). Modern Approaches to Understanding and Managing Organizations

[6] Borys, David (2014). Organisational Culture. In: Safety Institute of Australia, The Core Body of Knowledge for Generalist OHS Professionals, Safety Institute of Australia

[7] Chomsky, Noam (1967). Verbal Behavior. By B. F. Skinner. In: Language. 35, Nr. 1, New York 1959

[8] DeJoy, David M. (2005). Behavior change versus culture change: Divergent approaches to managing workplace safety. In: Safety Science 43 (2005) 105 - 129

[9] Dekker, Sidney (2015). Safety Differently. Human Factors for a New Era

[10] Dekker, Sidney W.A.; Nyce, James M. (2014). There is safety in power, or power in safety, In: Safety Science 67 (2014), 44-49

[11] Eichendorf, Walter; Bollmann, Ulrike (2014). Future approaches to a culture of prevention, In: Proceedings of the International Symposium on Culture of Prevention - Future Approaches, 39-49

[12] Seoul Declaration - On Safety and Health at Work (2008). XVIII World Congress on Safety and Health at Work: www.seouldeclaration.org

[13] Fahlbruch, Babette; Schöbel, Markus (2009). Vom "Newcomer" zur Selbstverständlichkeit: Rück-, Ein- und Ausblicke zur Sicherheitskultur, in: Ludborzs, B.; Nold, H. (Eds.), Psychologie der Arbeitssicherheit und Gesundheit. Entwicklungen und Visionen 1980-2008-2020, 48-60

[14] Grounded Theory (2015). https://de.wikipedia.org/wiki/Grounded_Theory

[15] Guldenmund, Frank W. (2010). Understanding and Exploring

\section{Safety Culture}

[16] Gutierrez, Rod (2012). Why don't people just follow the rules? A psychologist's explanation of safety management beyond behavior based safety

[17] Hale, Andrew R.; Hovden, Jan (1998). Management and culture: the third age of safety. A review of approaches to organizational aspects of safety, health and environment

[18] Haukelid, Knut (2008). Theories of (safety) culture revisited An anthropological approach, In: Safety Science 46 (2008) $413-426$

[19] Health \& Safety Laboratory (2013), Measuring the safety climate in organisations. Reduce injuries and costs through cultural change (White paper)

[20] INSAG - International Nuclear Safety Advisory Group (1988)

[21] Koch, Lutz (2015). Lehren und Lernen. Wege zum Wissen

[22] Lyotard, Jean F. (1987). Der Widerstreit, Original: Le Differend, Paris 1983

[23] Lyotard, Jean F. (1986). Grundlagenkrise, In: Neue Hefte für Philosophie 26 (1986) 1-33

[24] Schein, Edgar H. (2009). The Corporate Culture Survival Guide. New and revised edition of $1^{\text {st }}$ edition 1999

[25] Schein, Edgar H. (2004). Organizational Culture and Leadership, $3^{\text {rd }}$ edition, $1^{\text {st }}$ edition 1985

[26] Strauss, Anselm; Corbin, Juliet (1996). Basics of Qualitative Research (1990, in German as Grounded Theory: Grundlagen Qualitativer Sozialforschung)

[27] Skinner, Burrhus Frederic (1973). Jenseits von Freiheit und Würde, Original: Beyond Freedom and Dignity, 1971

[28] Skinner, Burrhus Frederic (1957), Verbal Behavior

[29] Strübing, Jörg (2007). Pragmatisch - interaktionistische Wissenssoziologie, In: Rainer Schützeichel (Ed.), Handbuch Wissenssoziologie und Wissensforschung, 127-138

[30] White, Jane (2015). Indicators for a Culture of Prevention

[31] Wildfeuer, Armin G. (2011). Praxis, In: Neues Handbuch philosophischer Grundbegriffe, Bd. 2, 1774-1804

[32] Wittgenstein, Ludwig (1977) Philosophische Untersuchungen, [Original: Basil Blackwell 1958]

[33] Wolff, Christian, (1720) Vernünfftige Gedancken von der Menschen Thun und Lassen: zu Beförderung ihrer Glückseeligkeit

[34] Wulf Christoph; Capeloa Gil, Isabel (Eds.) (2015). Hazardous Future. Disaster, Representation and the Assessment of Risk

[35] Wulf, Christoph; Jörg Zirfas (2013). Handbuch Pädagogische Anthropologie. Japanese translation by Yasuo Imai and Midori Takamatsu, 2015

[36] Wulf Christoph (2012), http://www.christophwulf.de/

[37] Zohar, Dov (2010). Thirty years of safety climate research: Reflections and future directions, in: Accident Analysis and Prevention, 42(2010), 1517-1522 